\title{
DECRECIMIENTO, CONVIVENCIALIDAD Y POSTDESARROLLO
}

\section{DEGROW, CONVIVIALITY AND POS-DEVELOPMENT}

\author{
Fernando Tula Molina \\ Universidad Nacional de Quilmes, Quilmes, Argentina \\ ftulamolina@gmail.com
}

Recibido: febrero de 2019

Aceptado: mayo de 2019

Palabras Clave: Decrecimiento, Convivencialidad, Posdesarrollo, Buen Vivir

Keywords: Degrow, Conviviality, Pos-development, Good Life.

Resumen: Este trabajo celebra y critica el artículo de Jairo Marcos Pérez, "Más allá del desarrollo: decrecimiento" en 2017. Se señalan los beneficios de ver en el concepto de "convivencialidad" de Iván Illich un sólido vector de toda política del posdesarrollo y no un concepto blando. Por otra parte, junto a André Gorz se señala que no es necesaria una ruptura total con el dinero y las mercancías para un verdadero decrecimiento, sino que basta con un proceso progresivo de descomercialización y recuperación del tiempo vivido, el cual puede caracterizarse como una retirada ordenada de la sociedad de consumo opulento.

Abstract: This paper celebrates and criticises the one by Jairo Marcos Pérez, "Beyond Development: Degrowth" (2017). It is indicated the benefits not to see the concept of "conviviality" proposed by Iván Illich as a soft one, but as a solid vector of degrow. In another hand, André Gorz's proposal to beguin a neatly quit from the opulent consumption socity allows not to broke completely with money and goods as criteria of true degrow. It is enough to beguin, soon as possible, a new strategy -centered on descomercialized activities- that get our lifetime back.

\section{Nota histórica: la justa medida}

Mucho de lo que la filosofía le debe a la matemática quedó inscripto en el frontispicio de la Academia de Platón: "No entre aquí quien no sepa geometría". Geográficamente esto nos conduce a la isla de Samos, donde alrededor de 580 antes de Cristo nació Pitágoras. Lamentablemente, en la actualidad el Pythagoreum Museum es sólo arqueológico y no contiene ninguna referencia a su obra. A pesar de ello, los turistas pueden conseguir un suvenir -la taza de la justa medida- diseñada en aquellos tiempos por Pitágoras para que sus alumnos avanzados se sirvan el vino. 
¿En qué consiste? En copones de cerámica con una protuberancia en el medio hasta una cierta altura, la cual queda resaltada por una línea exterior claramente visible. El copón funcionaba como un sifón, es decir, contenía un conducto que ligaba el fondo con tal límite y una salida por la base. Si alguien excedía tal línea, la presión hidrostática activaba el sifón y el alumno perdía no sólo el vino que se había servido en exceso, sino que la totalidad era chupada por el sifón y expulsada hacia abajo.

\section{Introducción. La discusión sobre el decrecimiento}

Como bien señalan los integrantes de Recerca i Decreixement, el decrecimiento se alimenta de vertientes diversas que desembocan en una pluralidad de propuestas, desde la bioeconomía a la ecología política, pasando por cooperativistas, nowutopistas y antiutilitaristas. Por su intermedio se trazan diversas líneas que conectan las iniciativas concretas de los activistas con propuestas de reestructuración de las políticas públicas. En este sentido, resulta aplicable "a toda la gama de imaginarios poscapitalistas basados en el decrecimiento" ${ }^{1}$. Puede decirse que el movimiento decrecentista es aquel que recoge, potencia y proyecta las objeciones al proyecto de crecimiento sin límite, el cual busca encerrarnos bajo la perspectiva única de necesidades crecientes. El punto de partida consiste en politizar el proyecto de consumo opulento, cuestionando no sólo su posibilidad -en un mundo finito- sino fundamentalmente su legitimidad, por suponer una igualdad de oportunidades inexistente. Lo que se busca es desenmascarar y denunciar el

1. D'ALISA, G. et. al., 2015, 12-13. carácter depredador, irresponsable y de poco futuro de una sociedad marcada por la norma de la productividad, un imaginario marcado por la idea de crecimiento $\sin$ fin, y una realidad laboral que bascula entre el mérito y la vigilancia.

De este modo, se trata de una discusión que interconecta diversos niveles; los problemas técnicos se convierten en éticos y políticos; la idea de prosperidad sin crecimiento parece una contradicción en sus términos que obliga a superarla en una reflexión mayor; la posibilidad de reconsiderar la jornada laboral también pone en juego nuestras actitudes frente a las cuestiones comunes; la propia idea de "responsabilidad" -contenido de cualquier política de regulación tecnológicase extiende sobre la reflexión tanto sobre nuestra condición alienada, como sobre nuestras posibilidades de emancipación.

\section{Niveles de análisis}

Ante tal entramado resulta útil distinguir los diversos niveles en los que se manifiesta el movimiento de objetores al crecimiento. Si bien tales niveles están interconectados, no son reductibles entre sí.

\section{I Biofísico}

Las consecuencias para los sistemas biofísicos de los procesos de crecimiento exponencial son conocidas -con detalle y en abundancia- al menos a partir del primer Informe Meadows, publicado originalmente por Dennis Meadows -a instancias del Club de Roma- en 1972. Se buscaba comprender las consecuencias de las complejas interacciones entre cinco grandes factores de la dinámica social: 
(i) Industrialización acelerada.

(ii) Crecimiento poblacional.

(iii) Expansión de la desnutrición.

(iv) Sobreexplotación de recursos no renovables.

(v) Deterioro ambiental.

Se entendió que se estaba frente a procesos que no sólo interactuaban entre sí, sino que cada uno respondía a una curva de crecimiento exponencial. ¿Consecuencias globales del sistema considerado en su conjunto? Inciertas.

Fundamentalmente en colaboración con su esposa, la ambientalista Donella Meadows (1941-2001) y el académico noruego -especialista en estratégica climática- Jørgen Randers, se determinaron las principales variables para la elaboración de los modelos y se organizaron las conclusiones:

(i) Si no cambia nada en las tendencias actuales de crecimiento poblacional, industrial, de contaminación, de producción de alimentos y de agotamiento de recursos, los límites de este planeta serán alcanzados en los próximos 150 años ${ }^{2}$.

(ii) Es posible alterar tales dinámicas de crecimiento y tratar de establecer condiciones de estabilidad económica, ecológica y social.

(iii) Si las personas deciden seguir este segundo camino, cuanto antes comiencen a trabajar mayores serán las posibilidades de tener éxito ${ }^{3}$.

En el prólogo a la última edición de 2012, Dennis Meadows -ya jubilado y profesor

2. El primero lo sitúa hacia 2030 debido a la crisis de recursos no renovables, hacia 2040 para el segundo debido a la crisis de polución, y hacia 2070 para el tercero a causa de la crisis de la alimentación (los restantes son variantes de estos tres).

3. MEADOWS, D. et. al., 1972, 23-24. emérito- destaca cómo fueron variando las actitudes frente al Informe en las diferentes décadas:

"En los años setenta la reacción principal fue de escándalo y crítica; en los ochenta, de ridículo; en los noventa de ignorancia y olvido de nuestra obra. La primera década de este siglo asistió a otro cambio. En la actualidad, existen un creciente interés y respeto frente a los resultados de nuestra investigación"4.

Tal renovado respeto se debe también a la recopilación de datos 1970-2000 llevada a cabo por la organización australiana CSIRO (Commonwealth Scientific and Industrial Research Organization), la cual confirma que se ha cumplido la evolución de los sistemas -graficada en 1972- bajo el escenario "standart run", es decir, aquel en el que no se introduce ninguna política para solucionar los problemas.

Tres años después del Informe Meadows, en 1975, el matemático rumano Nicholas Georgescu-Roegen (1906-1994) introduce el término "bioeconomía" para referirse a las raíces biológicas de los procesos económicos. Los recursos materiales se degradan irremediablemente y sus efectos nocivos se acumulan imponiendo restricciones precisas al desarrollo económico. Aquí los principales argumentos para el decrecimiento son estrictamente físicos.

Basado en los estudios sobre las transformaciones de calor en trabajo mecánico del físico e ingeniero francés Nicolas Sadi Carnot (1796-1832), Georgescu Roegen deriva una física del valor económico a partir de una distinción fundamental entre materia de baja entropía -con valor económico- y de alta entropía, sin valor económico. Su fundamento es que la energía puede encontrarse en dos estados:

4. MEADOWS, D. et al., 2012, 19. 
(i) Libre (utilizable, pe. carbón).

(ii) Ligada (inutilizable, pe. energía térmica de los mares).

Mientras la energía libre mantiene una estructura que permite diferenciar sus niveles, la energía ligada es energía caóticamente disipada. Por tal motivo, Georgescu ve en la carrera por el desarrollo económico una enorme miopía: la de suponer -a diferencia de la concepción entrópicaque la abundancia está desprovista de consecuencias ecológicas, y que luego de los procesos económicos el mundo vuelve a sus condiciones iniciales. Se trata de una ilusión basada en la supuesta reversibilidad postulada a partir de la ignorancia de las leyes de Carnot. Es por este motivo que el proceso económico se representa como un vaivén entre producción y consumo en un sistema cerrado.

\subsection{Político}

Desde un punto de vista político, ni el Informe Meadows ni los argumentos de Georgescu Roegen pretenden que el hombre vuelva a las cavernas. Por el contrario, Georgescu explícitamente observa que "sería tonto renunciar a los beneficios de nuestra evolución exosomática" 5 . De lo que se trata, es sentar las bases para una política tecnológica inteligente que calcule los costos no en dinero, sino en función de los materiales de baja entropía. Su criterio tendrá que ver con la manera que proyectemos los diferentes escenarios: "Serán inteligentes aquellas políticas y conductas que minimicen el arrepentimiento"6.

5. GEORGESCU ROEGEN, N., 2008, 113.

6. Ídem, 139.
Ahora bien, ¿es posible alcanzar mayores grados de responsabilidad y gobernanza en la sociedad actual? Resulta claro que las condiciones son fuertemente desfavorables. Como observa el periodista y ambientalista francés Hervè Kempf, esto se volvió patente en la cumbre climática de Johannesburgo de 2002, a la cual -a diferencia de la de Rio de 1992- no asistieron los Ministros de Medio Ambiente sino los de Economía y de Relaciones Exteriores. De este modo, a pesar de las advertencias ecológicas -y de la seriedad de los datos involucrados- cada vez resultó más explícito cómo los límites políticos se diluyen en las diversas instancias internacionales (G7, FMI, OMC, Banco Mundial), a través de las Tres D: la desintermediación financiera, la desegmentación de los mercados y la desregulación social.

Por otra parte, luego del 11-S la posibilidad de establecer democráticamente límites políticos al proyecto de crecimiento sin fin se vio drásticamente limitada. Efectivamente, tanto las libertades públicas como las garantías quedaron restringidas por tres grandes políticas, sobre las que Kempf aporta datos elocuentes: cárcel para los pobres ${ }^{7}$, criminalización de la oposición ${ }^{8}$, vigilancia digital ${ }^{9}$.

7. En 2010 EEUU tenía 738 encarcelados cada 100000 habitantes, más de 4 veces la cifra de 2005 y 7 veces más que Francia. Pero la población carcelaria era dispar. Entre 25 y 29 años 11,9 $\%$ eran afroamericanos, $3,9 \%$ hispanos, y $1,7 \%$ blancos.

8. La indignación se tilda de vulgar, la opinión divergente se reduce a militancia y la crítica a los poderosos es vista como anticuada y se utiliza a la justicia con el fin de encarcelar a los líderes opositores. Lula preso es uno de los ejemplos más claros al respecto.

9. En 2007 el Reino Unido de Tony Blair contaba con 25 millones de cámaras, una cada 2 adultos. Cfr. KEMPF, H., 2011, 121, 130, 125. 
De todos modos, el propio carácter desfavorable de las condiciones a la vez potencia y refuerza las objeciones que alimentan las luchas, la resistencia y los proyectos alternativos.

\subsection{Socioeconómico}

En su obra más conocida -Prosperity without Growth- el economista inglés Tim Jackson muestra cómo se mantienen no sólo en pie, sino cada vez más visibles los tres grandes cuestionamientos que deben conducirnos a renovar la idea de "contrato social":

(i) Posibilidad. La actual visión de progreso -monetarista y de mercados desregulados- resulta inalcanzable por no contemplar la capacidad del planeta de absorber la actividad económica.

(ii) Legitimidad. Se trata de reconocer como mostró la crisis del 2008- que el mito del crecimiento ha fallado en lograr economías sostenibles, ni en términos ecológicos ni en términos financieros.

(iii) Responsabilidad. A esta combinación de no atender a los límites, ni los de la naturaleza ni los de la justicia, Jackson la considera como característica de nuestra época: "Es ésta la era de la irresponsabilidad y debe acabar cuanto antes" 10 .

Su propuesta consiste en un proceso de alfabetización ecológica de la macroeconomía, una nueva gobernanza a partir de redefinir la noción misma de "prosperidad" de modo que tenga en cuenta la cohesión social y el impacto ecológico. En este punto Jackson expande las reflexiones del filósofo y economista bengalí

10. JACKSON, T., 2011, 41.
Amartya Sen, realizadas a partir de distinguir entre tres nociones de "bienestar":

(i) Opulencia.

(ii) Utilidad.

(iii) Florecimiento humano.

Su diagnóstico es que el aspecto defectuoso de la sociedad de consumo reside en estar centrada en las mercancías, por lo que nunca puede decirse cuándo es suficiente. Frente a esta situación, o seguimos la inercia habitual o intentamos un viraje estratégico para evolucionar desde el primer al tercer sentido de "prosperidad". Una vez que ello sucede resulta manifiesto que "no estamos frente a un escenario de libertades absolutas, sino antes bien frente al reconocimiento de nuestras capacidades limitadas"11.

La originalidad de su análisis consiste en vincular tal objetivo con la masa monetaria. Esto le permite hacer cálculos más específicos y concluir sobre la necesidad de un proceso de descarbonización de cada dólar: "cada dólar no debería superar los 6 g CO2, lo cual es un valor 130 veces menor al actual"12.

Por otra parte, si bien suele afirmarse que el empleo depende exclusivamente del crecimiento económico duradero, nuevamente Kempf muestra cómo entre 1949 y 2008 la población activa en Francia aumentó 48\%, pero la tasa de desempleo se multiplicó por 10; a su vez, entre 1971 y 2009 en España el PBI se multiplicó por 3, mientras que la población activa sólo lo hizo por 1,5 . Se ve entonces que, más allá de las promesas, la única correlación manifiesta es el aumento del PBI y el aumento del desempleo y de la precarización laboral. Por tales motivos Kempf

\section{1. Ídem, 71 .}

12. Ibíd., 109. 
concluye que "la destrucción del empleo es el resultado directo, lógico y esperable del crecimiento económico"13.

De este modo, la celebración del aumento del PBI refleja la elección tácita de perpetuar el orden vigente, es decir, una sociedad que ha naturalizado los imperativos de la industrialización y que, consecuentemente, se organiza en función del consumo forzado y la cultura del descarte. Por otra parte, el slogan, en principio ingenuo, "consumir menos para vivir mejor", en realidad obliga a prestar atención a un punto que ha quedado ciego en nuestra cotidianidad, velado por el imaginario del progreso y la prosperidad: ¿Podemos ser ricos y no ser felices? ¿Qué es la felicidad? Tales preguntas fueron abordadas por el economista de la London School of Economics, Richard Layard, quien buscó comprender la paradoja por la cual cuando las sociedades occidentales se volvieron más ricas, sus integrantes no se volvieron más felices ${ }^{14}$.

Inspirado en el utilitarismo del filósofo y economista inglés Jeremy Bentham (1748-1832), Layard considerará que la mejor política pública es aquella que produce más felicidad, por lo que podrá decirse que los países ganan en felicidad en la medida en que distribuyen mejor su renta. La razón de ello -como explica A. Sen- reside en que cuando el dinero va de ricos a pobres, la persona pobre gana

13. KEMPF, H., 2011, 176.

14. Para Layard la felicidad no resulta difícil ni de definir ni de medir. Efectivamente, resulta sencillo reconocer a una persona feliz, pero además "podemos preguntarles a las personas cómo se sienten, pedir una evaluación independiente o incluso medir la actividad eléctrica en la parte relevante del cerebro. Lo cierto es que se trata de sentirse bien, aprovechar la vida y desear que esa sensación se mantenga" (LAYARD, R., 2008, 29). más felicidad de la que la rica pierde ${ }^{15}$. De este modo, el "principio de felicidad mayor":

(i) Ayuda a encontrar las reglas.

(ii) Ayuda a escoger la acción cuando las reglas están en conflicto.

La hipótesis de Layard -contraria a la de Thomas Hobbes- es que el individualismo falló y que, si realmente deseamos ser felices, necesitamos un concepto de "bien común" al cual contribuir. No sólo es falso considerar a la cooperación humana como resultado exclusivo del miedo y el castigo, sino que es por la vía de la cooperación -antes que por la de la competencia- por la que podemos encontrar nuestra felicidad.

Sin embargo, como observa el principal promotor del decrecimiento -el sociólogo francés Serge Latouche- tales cuestionamientos chocan frontalmente con casi la totalidad de los regímenes políticos contemporáneos -sean liberales, comunistas, dictatoriales o democráticos- dado que todos comparten el supuesto productivista y miden su crecimiento a través del PBI. Es bajo este telón de fondo que "un posicionamiento decrecentista resulta claramente como un OVNI en el microcosmos del pensamiento político" ${ }^{\prime 16}$.

\subsection{Sociocultural}

Tanto Tim Jackson como Hervè Kempf fueron influenciados y dieron continuidad a las tempranas observaciones del eco-

15. "En los países con más de 20000 dólares per cápita, la renta adicional no está asociada a mayor felicidad... La renta extra es realmente valiosa cuando saca a las personas de la pobreza extrema" (Ídem, 50-51).

16. LATOUCHE, S., 2009, 7. 
nomista estadounidense Torstein Veblen (1857-1929). Veblen había señalado con agudeza sobre cómo el lenguaje de los bienes materiales se liga inextricablemente con la dimensión inmaterial de la prosperidad $^{17}$. En una ruptura radical tanto con el capitalismo como con el marxismo, Veblen plantea que la producción no es insuficiente y que el régimen natural de las sociedades no es la privación: "no son nuestras necesidades, sino el juego social lo que no tiene límites"18. De este modo -y de la mano de la teoría marginalistalas reglas económicas se transforman en reglas de consumo.

Las necesidades sociales señaladas por Veblen constituyen un fuerte motor para seguir por la vía del crecimiento, aunque ello no aumente necesariamente nuestra felicidad. Por el contrario, Latouche, cita al escritor y publicista Frédéric Beigbeder al decir: "Soy un publicista. Hacerlos babear es mi misión. En mi oficio nadie desea vuestra felicidad, porque las personas felices no consumen" 19 .

Por otra parte, al tratarse de un camino sin fin, los límites morales rápidamente se evaporan en la cultura de la transgresión. Por tal motivo, para alcanzar alternativas de cambio estructural es necesario comenzar por desmantelar la visión materialista de la prosperidad. No se trata de un planteo teórico o de una crítica terminológica, sino de "la denuncia del tiempo de consumo como un falso tiempo libre, un tiempo alienado que habría que procurar disminuir en aras de la emancipación"20.

17. Cfr. JACKSON, 2011, 78; KEMPF, H., 2011, 102.

18. KEMPF, H., 2011, 94.

19. LATOUCHE, S., 2014, 92.

20. BAYÓN et. al., 2012, 47. André Gorz ya lo había anunciado: "Una vez que el trabajador ha
Queda claro que las dificultades no son menores. No sólo la clase media internacional resulta más un vector de consumo que de sobriedad, sino que todo límite cultural choca de lleno con el dictum de la metafísica de la ilimitación: "No, no puede haber límites. El progreso de la ciencia y la tecnología así lo demuestran". En este punto Latouche observa cómo el rechazo a los límites del conocimiento "se vincula con el negacionismo de los límites ecológicos, con la religión del crecimiento y el sueño de la omnipotencia"21.

Pero la propia pregunta sobre qué es posible hacer frente a la compleja y conflictiva situación de consumo forzado remite -como pregunta previa- a preguntarnos por el sujeto de cambio; es decir ¿Quién va a hacerlo? ¿Quiénes van a modificar su pauta de comportamiento y consumo? Puede adoptarse una actitud escéptica y responder, como lo hace el ensayista francés Michel de Houellebecq: "Nadie"22. Si bien esta respuesta no resulta descabellada cuando nos enfocamos en la inercia de las prácticas provenientes de las instituciones de la modernidad, no sucede lo mismo si nos enfocamos en los márgenes e intersticios que tales instituciones dejan libres; en ellos florecen alternativas sociotécnicas con otros modos de relación entre la naturaleza, el espacio y el futuro. Cada una de ellas abre horizontes de convivencia alternativos al del círculo poco feliz: publicidad-trabajo-consumo.

sido reducido a mercancía, no sueña sino con mercancías (compensatorias)". GORZ, A., 2011, 112.

21. LATOUCHE, S., 2014, 100.

22. Con ello Houellebecq reformula lo que $\mathrm{H}$. Arendt había llamado "responsabilidad de nadie"; es decir-como señala Z. Bauman- "la costumbre de disolver la responsabilidad en el cuerpo administrativo" (BAUMAN, Z., 2013, 95). 
Este movimiento hacia relaciones sociales más fraternas y menos ligadas a la competencia ya ha comenzado, desde los movimientos de Seattle en 1999 y la organización progresiva del Foro Social Mundial. Efectivamente, en la actualidad existen innumerables movimientos antiglobalización y permaculturales que -a diferencia de Houellebecq -y de existir la posibilidad- responderían: "Nosotros". No se trata de buscar la salida individual en los márgenes del derrumbe. Por el contrario, se trata de la diseminación de las alternativas actualmente activas, como es el caso de los cientos de ciudades y comunidades en transición-hacia la resiliencia ambiental y social- que siguen los principios delineados por Rob Hobkins ${ }^{23}$.

\subsection{Humano}

Desde un punto de vista teórico, fue el filósofo alemán Hans Jonas (1903-1993) quien defendió el "principio de responsabilidad" no sólo como guía, sino como contrapunto necesario al falso optimismo de creer que la tecnología se encargará de arreglarlo todo. Tal principio fue presentado como un nuevo punto de partida, concedida la caída de los tres grandes supuestos de la ética clásica: la idea de una naturaleza humana fija, la confianza en poder determinar lo bueno y lo malo y la posibilidad de definiciones rigurosas. En su opinión: "Se torna necesario reconocer que la ignorancia se vuelve el otro lado obligado del saber"24.

La indagación de Jonas se propone determinar si, sin restablecer la categoría

23. HOPKINS, R., 2008, The Transition Handbook. From oil dependency to local resilience, Totness: Green Books.

24. JONAS, H., 2011, 41. de lo sagrado, es posible tener una ética que controle los poderes de la alta tecnología, admitiendo que estamos obligados a seguir ampliándolos. En su opinión -y en línea convergente con el Informe Meadows-son nuestras propias nuevas capacidades tecnológicas -y su potenciación geométrica- las que imponen una ética de previsión y responsabilidad. Jonas parte del modelo de responsabilidad filial padre-hijo y formula su principio como el "no poner en riesgo las condiciones necesarias para la conservación indefinida de la humanidad sobre la tierra" 25.

La mayor dificultad parece residir en el excesivo dinamismo que marca nuestra contemporaneidad. Nos movemos en una expectativa de constante progreso técnico, masivamente visible en la rápida construcción de la sociedad digital. Y si bien es posible orientar políticamente tal impulso, la pregunta correcta no es si el hombre conseguirá adaptarse, sino qué condiciones de adaptación deben permitirse ${ }^{26}$.

En definitiva, Jonas distinguirá dos horizontes de responsabilidad:

(i) Uno más próximo donde -gracias al conocimiento analítico- podemos calcular los efectos de nuestra acción.

(ii) Otro más amplio que abarca al conjunto acumulativo de interacciones humanas.

Frente a ellos, y al igual que en el nivel sociopolítico, o regresamos al escepticismo en la línea de Houellebecq o, por el contrario, coincidimos con el historiador británico Tony Judt (1948-2010), quien

\section{5. Ídem, 49.}

26. Se trata de la misma preocupación que manifestará Gorz: "¿En qué medida al adaptarnos a este mundo al que dan forma los instrumentos de nuestra civilización, no nos desadaptamos de nosotros mismos?" (GORZ, A., 2011, 117). 
-junto al filósofo estadounidense Ernest Nagel (1901-1995)- desarrolló el concepto de "responsabilidad post-mortem" en la Universidad de Nueva York:

"Seguimos en la vida de los individuos por los que respondemos... la memoria que dejamos del conjunto de ideas que teníamos -y de las razones para continuar utilizándolasson un conjunto de responsabilidades que tenemos ahora... por lo que hay argumentos para actuar ahora como si fuéramos a estar ahí para asumir la responsabilidad por nuestras palabras y hechos; por la vida en el futuro, aunque no sea nuestro propio futuro" ${ }^{27}$.

Ahora bien, si bien la discusión filosófica resulta importante para ayudar a reorientar las prácticas, lo cierto es que un posicionamiento decrecentista nos interpela fundamentalmente en nuestras prácticas de consumo. Son nuestros propios deseos los que deben reconsiderarse a la luz de una mayor conciencia política sobre sus implicancias. De este modo, el "viraje estratégico" mencionado al comienzo supone desplazar la idea de "responsabilidad" desde el orden, el trabajo y el consumo hacia prácticas de cuidado. Al respecto, podemos considerar cómo disminuir el dinamismo de la carrera laboral y de consumo resulta beneficioso al menos en dos dimensiones fundamentales:

(i) Salud individual.

(ii) Paz social.

Con relación a la salud, al hablar de felicidad Layard observa incidentalmente la conexión directa que hay "entre actividad cerebral y humor, y entre humor y mejora del sistema inmunológico"28. Si bien él no desarrolla este punto sí lo hace James Smart, un neurocientista estadounidense formado en la Universidad de Lund. Su

27. BAUMAN, Z. 2013, 161.

28. LAYARD, R., 2008, 35. investigación principal fue sobre la influencia del ruido en niños con Trastorno por Déficit de Atención e Hiperactividad (TDAH). Tal investigación lo llevó a interesarse por la Red Neural por Defecto (Default-Mode-Network, DMN) descubierta en 2001 por Marcus Raichle de la Universidad de Washington, St. Louis. Esta red neural -también llamada Red de Estado de Reposo- tiene una característica notable: "se activa sólo cuando no hacemos nada, adquiriendo grados mayores de robustez y coherencia"29.

Ante tal descubrimiento, Smart vio la necesidad de escribir sobre la importancia del ocio para incrementar el nivel de ruido interno del cerebro y habilitar tal resonancia de coherencia. A esta concepción la llamará concepción "científica" del cerebro y la opondrá a la concepción luterana y cristiana que liga al hombre a la ética del trabajo. Smart concluye del mismo modo que lo hará la ecología política delineada por A. Gorz: "la solución radica en crear una verdadera sociedad post-trabajo que libere las energías humanas; si bien el camino no está a la vista, tengo fe en que la respuesta está a nuestro alcance" 30 .

En cuanto a las posibilidades de fomentar la paz colectiva, la filósofa catalana Irene Comins Mingol ha propuesto un necesario cambio curricular para encaminarnos hacia la paz. Comins Mingol muestra la posibilidad de una transformación radical de nuestras actitudes -sobre la relación entre lo individual y lo colectivo- justamente a partir del hecho de que las actitudes pueden ser aprendidas y practicadas. Al igual que en el caso de Layard, su punto de partida es necesariamente anti-hobbesiano:

29. SMART, J., 2014, 52.

30. Ídem, 176. 
"Los seres humanos somos competentes no sólo para matarnos, como muestran a diario los informativos, sino también para ayudarnos, solidarizarnos, cuidar del otro y hacer las paces. La propuesta de una educación para la paz busca superar la esquizofrenia cognitiva entre lo que deseamos (paz) y aquello que investigamos, vemos y contamos (violencia)"31.

También en la línea de A. Sen, Comins Mingol entiende por "cuidado" una competencia que permite proyectar hábitos de convivencia. Paradójicamente, si buscamos autonomía, lo tenemos que hacer de modo heterónomo; es decir, a través del otro: no renunciamos a nuestra autonomía, la heteronomizamos"32. Aunque Comins Mingol no lo menciona, su propuesta viene a cumplir lo que buscaba Layard, es decir "un currículum con un objetivo básico: la conciencia de un propósito global más amplio que el propio yo"33.

Bajo este abordaje ya no se trata simplemente de actuar con justicia, sino de no girar la cabeza ante las necesidades de Ios demás: "A diferencia de la ética de la justica, para la ética del cuidado la pregunta no es ¿Qué es lo justo?, sino ¿Cómo responder?"34. Por tal motivo, y al igual que para Layard, la implicación en la comunidad es la vía para un correcto desarrollo moral.

Tal abordaje a partir de prácticas de cuidado resulta un agente promotor tanto de participación como de cambiar el enfoque hacia la interconexión entre emociones y razones. Se trata de expresar el hecho de que "el sentimiento de utilidad e interconexión aumenta la autoestima personal y la feli-

31. COMINS MINGOL, I., 2009, 15.

32. Ídem, 69.

33. LAYARD, R., 2008, 266.

34. COMINS MINGOL, I., 2009, 52. cidad... la recompensa es el acto mismo: aquí el más dispendioso es el más rico"35.

\section{4. "Más allá del desarrollo: decrecimiento"}

Teniendo esto en cuenta, es para celebrar la aparición del artículo de Jairo Marcos Pérez: "Más allá del desarrollo: decrecimiento". Se trata de un trabajo que actualiza la discusión, clarifica conceptos y nos encamina a una reflexión diferente con fines de transformación. Su primer acierto consiste en considerar a la noción de "lo suficiente" como divisora de aguas, no sólo sobre la comprensión de las actividades productivas, sino del propio modo de ser humano ${ }^{36}$. Sobre ella convergen dos discusiones que nos afectan de modo directo y que parecen nunca tener suficiente: la del desarrollo tecnológico y la de la acumulación del capital. Si a esto sumamos el proceso avanzado de financiarización de la economía global, quedamos atrapados en una lógica que el autor no duda en calificar como perversa, la que se considera "emancipada de todo límite físico"37.

Un segundo punto a resaltar es lo que Pérez llama un matiz clave: entender que "el subdesarrollo no es la etapa previa del desarrollo, sino su producto"38. El malestar y las dificultades para vivir con dignidad en el mundo periférico resultan efectivamente de la tercerización de los costos -pero no de los beneficios- de las prácticas de comercialización y consumo opulento. Por otra parte, se trata de la lógica del capital que niega de modo sis-

35. Ídem, 92.

36. PÉREZ, J. M., 2017, 468.

37. Ídem, 469.

38. Ibíd., 471. 
temático las abundantes evidencias sobre el hecho de que nos encontramos en un curso de maldesarrollo. Para entenderlo, como señala Pérez, ayuda a estar atentos al hecho de que siempre se habla de desarrollo de modo genérico, sin explicitar nunca su dimensión política, es decir, "de qué desarrollo se trata, ni desde dónde ni hacia dónde va, tampoco a quiénes beneficia, ni en qué ni por qué"39.

A partir de aquí, Pérez resalta las virtudes de utilizar el decrecimiento como un camino alternativo que abandona un mito perverso para muchas comunidades tanto biológicas como humanas. Al igual que H. Jonas, Pérez resalta la relevancia del "reconocimiento de la incertidumbre" y la necesidad de desplazarse desde una ética utilitarista a una pluralista. Es decir, no se trata de sancionar como nuevo dictum, "menos es mejor", al naturalizado por las sociedades industriales y de consumo, "más es mejor". Lo que se busca es el florecimiento de otras lógicas y prácticas que no reproduzcan las instituciones y los ideales de la modernidad.

En este sentido, agrega Pérez, el enfoque pluralista se aleja tanto de la idealización de las tradiciones locales, como de buscar decirles a las personas lo que tienen que hacer. Cada comunidad debe liberarse a sí misma de los imperativos del desarrollo, atendiendo a sus condiciones y dinámicas locales. De este modo, el decrecimiento no se presenta como un horizonte alternativo, "sino como una herramienta de construcción de transformaciones traducibles en múltiples experiencias"40, como - por ejemplo- la de los economistas heterodoxos por desmaterializar la economía

39. Ibíd., 472.

40. Ibíd., 478. o las preocupaciones feministas por el cuidado y la vida.

En este sentido, Pérez concluye: "el reto del decrecimiento es aprender a producir valor y felicidad reduciendo progresivamente la utilización de materia y energía" 41 . En todos los casos se aspira a la transformación vía el compromiso que liga lo individual a lo colectivo. Su propuesta consiste en profundizar el modelo de S. Latouche, quien ya había visto la necesidad de ampliar el clásico modelo de las 3R hacia un programa radical basado en $9 R^{42}$. Para ello utiliza las 5R adicionales propuestas por el economista catalán Joan Martínez Allier y las organiza sobre el final en un ilustrativo gráfico que ayuda a conceptualizar la complejidad y a orientar las alternativas ${ }^{43}$.

A pesar de lo señalado, sobre el final Pérez hace dos movimientos que -a mi juicioatentan contra sus propios objetivos. El primero es incidental, consignado en nota al pie, donde sigue la línea de S. Latouche y C. Taibo al resaltar como centro de la idea

\section{1. Ídem.}

42. "Reevaluar (sustituir los valores dominantes actuales), Reconceptualizar (salir del imperialismo de la economía), Reestructurar (adaptar el aparato de producción y las relaciones sociales), Redistribuir (repartir los elementos del sistema), Relocalizar (pensar globalmente, actuar localmente), Reducir (disminución de la huella ecológica), Reutilizar-Reparar (desanudar la sociedad del consumo), Reciclar (transformar los desechos ya inútiles en fuente de materias primas disponibles para un nuevo uso) y Ralentizar (rehabilitar el tiempo)" (ibíd., 479).

43. "Romper (desanudar las múltiples dependencias Norte-Sures), Renovar (volver a tejer el hilo de la historia interrumpida por la colonización, el desarrollo y la globalización), Reencontrar (apropiarse de una identidad propia), Reintroducir (incluir los valores y prácticas olvidados por las economías) y Recuperar (rescatar técnicas y habilidades tradicionales)". (Ídem). 
de decrecimiento su carácter alborotador, "en detrimento de conceptos más blandos como 'convivencialidad', 'sencillez voluntaria', 'sobriedad' o 'ecosocialismo'" 44 . El segundo, sobre el final, a mi juicio pone en riesgo todo el argumento de ser considerado poco realista, al establecer como "criterio para un verdadero decrecimiento la ruptura total con la producción de mercancías y de dinero" (mi cursiva)" 45 .

A continuación, en un contrapunto que busca fortalecer su argumento principal, intentaré mostrar que basta con volver la mirada sobre los primeros objetores al proyecto de crecimiento $\sin$ fin para que tales dificultades se solucionen. Con este fin, ampliaré las sus breves referencias sobre la obra del primer defensor y divulgador del decrecimiento, el multifacético pensador austríaco, Iván Illich (1926-2002), y sobre la del principal promotor de la ecología política, el periodista y filósofo francés André Gorz (1923-2007). Específicamente buscaré poner de manifiesto que haríamos mejor en ver en el concepto de "convivencialidad" un sólido vector transversal de los diferentes decrecimientos. Por otra parte, defenderé como una posición más realista la idea de "retirada ordenada" proveniente de la ecología política.

\section{Convivencialidad y autolimitación}

"Una sociedad que limitara el poder de las herramientas por debajo de los umbrales en que aquellas empiezan a usurpar las facultades autónomas de la gente debería llamarse convivencial" 46 .

44. Ibíd., 476, n. 36.

45. Cfr. ibíd., 476.

46. Illich, I., 2011, 21.

\section{5.l Energía y equidad}

Un año después de la publicación del Informe Meadows, Iván Illich puso de manifiesto la imposibilidad de avanzar hacia sociedades más equitativas manteniendo un modelo del consumo energético creciente. Su libro Energía y Equidad reelabora tres artículos publicados originalmente en Le Monde en el mes de mayo de 1973. Tempranamente se preguntaba allí si no estaremos sufriendo un período de ilusión tecnológica colectiva que nos conduce a un espiral de crecimiento sin fin y despilfarro energético sin límite. Con cierta ironía, utiliza la expresión "cinturón de seguridad ideológico" para referirse a la "obligación de consumir dosis cada vez más altas de energía"47.

¿Cómo salir de este círculo de dependencia e ilusión tecnológica? Illich no aborda estas preguntas del lado de la ínfima minoría que realmente aprovecha el confort del modelo de consumo opulento, sino de la amplia mayoría que - al aceptar la cosmovisión de los ricos"aceptan la dependencia del motor y se imponen a sí mismos un hándicap en la carrera por el crecimiento"48. Es esta situación la que describe -en una de sus expresiones más conocidas- como de "pobreza modernizada"49.

De este modo, discutir la crisis de energía implica posicionamiento político. A mano izquierda se abre la transición a una economía postindustrial que ponga el énfasis en la satisfacción austera de todas las aspiraciones realistas. A mano derecha, la opción tecnocrática, se abre

47. Illich, I., 1975, 338 .

48. Idem, 328.

49. Illich, I., 1978, 488. 
la escalada del crecimiento con énfasis en un progresivo control social para la capitalización de los bienes y servicios.

Lo innovador del razonamiento de Illich consiste en su idea de "equidad", la cual se alcanza a través de la generalización de un menor consumo energético. Desde esta perspectiva, la limitación de toda la circulación a una velocidad del orden de $25 \mathrm{~km} / \mathrm{hs}$. permitiría mayor equidad y libertad a nivel colectivo. Con ello Illich buscó promover otra política tecnológica donde la idea de "eficiencia" se asocie con lo óptimo y no con lo máximo ${ }^{50}$. La velocidad óptima será aquella que se encuentre por sobre un umbral inferior (por debajo del cual resulta insuficiente), y por debajo de un umbral superior (a partir de los cuales resulta nociva). A este último Illich denomina "punto crítico" -Punto K- donde lo cuantitativo se transforma en cualitativo.

\subsection{Herramientas justas}

En 1978 Illich escribe La convivencialidad. Allí desarrolla la tesis sobre la necesidad de determinar los umbrales de nocividad de las herramientas, según estas se volvieran contra su fin o amenazaran al hombre. A partir de entonces, llamará "convivencial" a aquella sociedad en la que las herramientas sirvan efectivamente a las personas y no a un cuerpo de especialistas. Esto no implica renunciar a nuestros conocimientos, sino evitar el supuesto tecnocrático por el que, gracias a la tecnología, siempre más adelante estaremos mejor.

50 . " $80 \mathrm{~km} / \mathrm{h}$. en las rutas porque a tal velocidad, la eficacia de los motores es máxima, y límites de $40 \mathrm{~km} / \mathrm{h}$ en los puntos congestionados para aumentar la cantidad de autos por km. de asfalto" (Illich, I., 1975, 359).
La situación ecológica actual impone objetivos superadores que permitan salir del mal desarrollo y retomar las proporciones convivenciales en las actividades sociales. Para escapar de la progresiva homogenización a la que conduce el orden tecnocrático hay reinstrumentalizar la sociedad de tal modo que aumente el control de las herramientas por parte de quienes las usan, entendido esto en sentido colectivo. Las herramientas justas serán aquellas que se encuentran dentro de los umbrales de convivencialidad, para lo cual deben responder a tres exigencias:

(i) Ser generadora de eficiencia sin degradar la economía.

(ii) No suscitar esclavos y amos.

(iii) Expandir el radio de acción personal.

\subsection{Investigación radical}

Teniendo en cuenta que Illich era un ingeniero formado, será desde un punto de vista ingenieril que llamará "investigación radical" al proceso destinado a fijar la instrumentación posible bajo un objetivo doble:

(i) Presentar criterios para determinar cuándo una herramienta alcanza el umbral de nocividad.

(ii) Inventar herramientas que optimicen el equilibrio de la vida y maximicen la libertad.

En definitiva, la idea de convivencialidad busca orientar los múltiples caminos de resistencia a través de la exploración consciente de la autolimitación, es decir caminos que se dirigen en un sentido contrario a los trazados por la lógica de la productividad industrial. La convivencialidad supone una empresa colectiva que busca limitar las dimensiones de las 
herramientas y defender los valores de sobrevivencia, equidad y autonomía creadora. Esto no implica suprimir los transportes interurbanos de alta velocidad, "a menos que ello impida garantizar al conjunto de la población la posibilidad de circular al ritmo que quiera" 51 .

\subsection{Umbrales de convivencialidad}

Illich emitió una temprana señal de alerta sobre el hecho de que las instituciones de la sociedad industrial -la educación obligatoria y la profesionalización- habían superado los umbrales de convivencia pacífica:

(i) El que genera dependencia: cuando una actividad social se confía a especialistas (pe. salud a los médicos).

(ii) El que genera escasez: cuando se jerarquiza el acceso a un servicio bajo el argumento de falta de recursos.

Por el contrario, la idea de "convivencia" tiene como fin construir márgenes suficientes que nos alejen de la escasez y la dependencia. Para ello Illich utiliza dos vectores:

(i) Destino colectivo: Pequeñas causas tienen grandes efectos que abarcan a todos por igual. Necesidad de reorientar nuestras prácticas hacia la reinserción en ciclos naturales.

(ii) Circuitos más cortos: Cuestionamiento de nuestro estilo de vida basado en globalizar los desplazamientos y las posibilidades.

Según este análisis, la convivencialidad se erige como objetivo y resultado de las políticas del postdesarrollo.

51. ILLICH, I., 2011, 399.

\section{Ecología política}

André Gorz conoció a Iván Illich en 1973, año en el que se inició una prolongada amistad y etapa de colaboración. Progresivamente Gorz extendió los argumentos de Illich a favor de la convivencialidad, y dio inicio a la ecología política como un proyecto cultural y político de resistencia. Por su intermedio se establecen los objetivos del postdesarrollo:

(i) Restablecer la correlación entre menos trabajo y menos consumo.

(ii) Aumentar progresivamente la autonomía y seguridad existencial de cada uno y cada una.

La ecología política sistematiza los cuestionamientos al modelo de consumo opulento y los reenfoca para trazar un claro camino hacia la reducción progresiva de la jornada laboral. No se trata sólo de reducir, sino de considerar que es la propia ideología productivista la que valoriza, perpetúa y -llegado el caso- remata la obra iniciada por el capital; es decir, la destrucción de las capacidades de autonomía. Por ello, no se trata simplemente de disminuir nuestro consumo, sino fundamentalmente de reconsiderar y reconfigurar la concepción burguesa de la riqueza que todo lo transforma en dinero. Es tal concepción la que ha impregnado tanto a la derecha como a la izquierda, a los gerentes como a los gerenciados, a los patrones como a los trabajadores.

Ahora bien, dado que la autonomía laboral sólo tiene sentido si se acompaña de una autonomía cultural y política que pueda prolongarse más allá del trabajo, la ecología política plantea la posibilidad de nuevas conexiones y reconexiones:

(i) Conectar el principio ecológico "Pensar globalmente, actuar localmente" con 
el principio que se impone a partir de nuestra situación actual: "Consumir menos, repartir mejor".

(ii) Desconectar del trabajo el derecho a tener derechos, especialmente a aquellos que no requiere trabajo o requieren menos.

En términos culturales, se trata de postular que la expansión de la esfera de la libertad supone que la esfera de la necesidad esté netamente delimitada. Efectivamente, la racionalidad económica no se aplica cuando el individuo es libre para determinar su nivel de necesidades. Este nivel puede variar, pero no deja de ser la categoría de lo "suficiente" la que regula el equilibrio entre el nivel de satisfacción y el volumen de trabajo para sí. Por el contrario, si se mide la riqueza en dinero, no existe lo suficiente.

\section{I La norma de lo suficiente}

La norma de lo suficiente se convertirá en el punto de convergencia de las tres líneas del pensamiento de Gorz:

(i) La autolimitación como proyecto social.

(ii) La reconstrucción de la sociabilidad vivida.

(iii) La liberación del tiempo laboral.

Se trata de una norma que proporciona un contenido específico para al cambio cultural que se reclama como precondición de transformación; el objetivo está puesto en buscar lo óptimo por el lado de lo mínimo, es decir, en hacer mejor con menos:

(i) Mejor: Mayor duración, facilidad de reparación y mantenimiento, facilidad de desmontar y menor consumo.

(ii) Con menos: Prácticas compartidas en el uso de equipamientos, talleres barriales, salas comunitarias de esparcimiento.
En tanto proyecto de resistencia se encuentra tensionado en dos grandes niveles:

(i) Dominación vs. Autonomía. La norma de lo suficiente procura funcionar como antídoto frente a la estrategia de dominación que consiste en incitar a que todos luchen por recursos escasos.

(ii) Desarrollo Humano vs. Crecimiento. Bajo la idea de "autoproducción de uno mismo" como patrón de riqueza, la norma de lo suficiente orienta las preguntas fundamentales: ¿Qué crecimiento necesitamos? ¿Cuál es la mejor manera de alcanzarlo?

\subsection{Retirada ordenada}

En 1981 -con la publicación de Adiós al Proletariado- se produce un punto de inflexión en la obra de Gorz. Una vez perdida la fe en que las reformas revolucionarias puedan provenir de una estrategia sindical, Gorz abandona la idea de proletariado como sujeto histórico. Efectivamente, ya no puede defenderse una idea que exige que cada uno se entregue completamente en el trabajo bajo una moral de la acumulación, simétrica de la moral burguesa del capital.

Más adelante, a fines de la década de 1990, Gorz ve la necesidad de dejar de hablar de "crisis del trabajo" con el fin de poner de manifiesto que en su lugar se ha instalado un sistema que lo suprime macizamente y "obliga a luchar a todos contra todos en busca de ese trabajo que el propio sistema abolió" 52 . Se trata de la misma perspectiva desalentadora ya anticipada por la filósofa Hannah Arendt

52. GORZ, A., 2004, 9. 
(1906-1975) de una sociedad basada en el trabajo, pero sin trabajo ${ }^{53}$.

Atendiendo a ello, Gorz comienza a dirigirse a aquellos que pierden su vida para ganarla y a la creciente mayoría de excluidos, expulsados, críticos y refractarios al sistema que de modo heterogéneo conforman una "no-clase" de "no-trabajadores". Mediante tales expresiones busca enfatizar que, a diferencia de la clase obrera tradicional, esta no-clase no es un sujeto social, no tiene unidad, misión trascendente o concepción de conjunto de la historia o de la sociedad. Por el contrario, se trata de subjetividad liberada por medio de la cual se abren las encrucijadas y las alternativas ${ }^{54}$.

A partir de allí, Gorz resaltará que, en el contexto de los Estados totalitarios "la conciencia individual se descubre clandestinamente como el único fundamento posible de una moral: la moral comienza siempre por una rebelión" 55 . Su fuente de sentido sólo puede surgir del derecho de cada uno sobre su propia vida, como un poder que cada individuo extrae de su propia existencia. Serán los propios individuos los que deban franquear los um-

53. "Lo que nos depara es la posibilidad de una sociedad de trabajadores sin trabajo, esto es, sin la única actividad que les queda. Ciertamente nada podría ser peor" (ARENDT, H., 2016, 13.

54. A este proceso Gilles Deleuze y Félix Guattari lo llamarán proceso original de subjetivación (cfr. DELEUZE, G. / GUATTARI, F., 2002, 125) y John Holloway lo asociará con la dialéctica de la inadecuación: "El arma de la dignidad es la otredad, el otro vivir, el otro hacer... una inadecuación dirigida - de modo explícito o no- en contra de eso donde no encajamos, es decir en contra de un mundo de explotación y destrucción" (HOLLOWAY, J., 2011, 55).

55. GORZ, A., 2001, 96. brales de transformación, con la multiplicidad propia de su heterogeneidad

Como también propondrá luego el teórico de la revolución irlandés John Holloway, toda revolución "comienza con microrevoluciones que abren un número suficiente de grietas en el sistema" ${ }^{56}$. El método de las grietas es el método de la micropolítica: "la cuestión principal no es la de los grados de radicalidad, sino conmover sentimientos, canalizar iras y sueños y hallar resonancias" 57 . Será en este mismo sentido que Gorz promueva retirarse ordenadamente de la sociedad de consumo opulento como vía micropolítica de transformación pacífica. En una línea convergente con las reflexiones del filósofo francés Giles Deleuze (1925-1995), Gorz coloca como objetivo último el gozo de sí mismo: "Cuando éste es descubierto en la praxis soberana, ya no es más posible hacer que se consuma y destruya lo superfluo al precio de lo esencial"58.

\subsection{El modelo de la sociedad dualista}

"El verdadero poder del capital reside en la centralidad que el trabajo conserva en la vida y en la conciencia de cada uno de nosotros" 59 .

56. HOLLOWAY, J., 2011, 95.

57. Ídem, 89.

58. GORZ, A., 1968, p. 134. "Hay un gozo inmanente al deseo, como si se llenase de sí mismo y de sus contemplaciones, no implica ninguna carencia: es ese gozo que distribuirá las intensidades de placer y que impedirá que se carguen de culpabilidad o de vergüenza" (DELEUZE, G., 2002, 160).

59. GORZ, A., 2004, 65. 
En un reportaje que le hicieran Martin Jander y Rainer Mainschein sobre la alineación, la libertad y la utopía - El hombre debe hacerse lo que es (1984) - André Gorz anuncia:

"Lo peor todavía está por llegar, es decir, el derrumbe financiero de grandes bancos, probablemente también de Estados; por ese motivo, las semillas que se han sembrado con el movimiento alternativo... podrían desarrollarse o hacer posible una delimitación clara de los frentes: de un lado, los partidarios de una sociedad del tiempo liberado y de la autoactividad creciente, independiente de los valores del dinero; del otro, los partidarios de la gestión de la crisis en economía dual y autovigilancia"60.

El punto de partida para este planteo fue la aceptación de que una parte importante de la producción no se presta a una gestión horizontal colectiva, por lo que hay que admitir una esfera de trabajos heterónomos. Por este motivo, "no podemos escoger entre identificarnos con el trabajo asalariado o eliminarlo, sino entre diferentes maneras de gestionar esa eliminación""61. Se plantea con ello el perfil de una sociedad dualista que se manifiesta en el interjuego las esferas autónomas y heterónomas. No se trata de bloques monolíticos sino de abanicos de actividades que, aunque responden a lógicas diferentes, conviven a través de varios niveles de contacto y comunicación.

El límite de la esfera heterónoma está dado por la conciencia que se tenga de la propia situación de alienación, es decir, de cuánto uno puede desear lo que hace. El límite de la esfera autónoma, es justamente el de su sustentabilidad en el tiempo. De este modo, se abre una socie- dad de multiactividades, donde no son las monetarias las que cargan con el sentido principal aunque sean siempre necesarias. Bajo el horizonte del decrecimiento florecen y adquieren vigor los círculos de cooperación, donde la reciprocidad serial funciona como alternativa, aunque no siempre completa, a la sociedad salarial.

El objetivo de aumentar la esfera autónoma "no es el de descansar más sino el de vivir más"62. Para ello se plantean tres condiciones:

(i) Autoorganización y cooperación productiva.

(ii) Satisfacción y desarrollo de competencias que pueden movilizarse en tiempo libre.

(iii) Sentido de finalidad.

\subsection{Renta de existencia}

¿Qué es la riqueza? Como se vio, esta es la pregunta fundamental. Concebida en términos sociales no resulta difícil ver que la riqueza se genera a través de las externalidades positivas que surgen del propio colectivo social, más allá de las contribuciones individuales. Es decir, todos contribuimos -aunque sea de modo indirecto e invisible- a la productividad económica, por lo que todos tenemos derecho a una existencia social.

Bajo este abordaje Gorz promovió la institución de una renta de existencia como política pública concreta. Desde el inicio quedó claro que tal renta debía tener el carácter de universal y suficiente "para no forzar a los desempleados a aceptar los empleos despreciados, penosos y des-

60. GORZ, A., 2010, 90.

61. Ídem, 89.

62. GORZ, A., 2001, 11. 
valorizados y convertirse en un subsidio para los empleadores"63.

La función de la renta de existencia consiste en hacer de la reducción metódica, programada y masiva del trabajo, el eje de una nueva política del tiempo. Su objetivo es el de restablecer el equilibrio en las sociedades industrializadas, las cuales producen cantidades crecientes de riqueza con cantidades decrecientes de trabajo. Entendida en tanto derecho, tal renta no está destinada a retornar al pleno empleo, sino que "impulsa a experimentar el pleno empleo de la vida" ${ }^{4}$. Sobre ella existen dos concepciones:

(i) Basada en la idea de que el capitalismo aprovecha los recursos desarrollados por las personas en su vida cotidiana, como capital fijo. Esta concepción rebaja todo trabajo a trabajo económico.

(ii) Como una estrategia alternativa al valor del trabajo. Su función consiste en restringir la esfera de creación del valor económico, por lo que no exige ni remunera nada.

En esta coyuntura se juega tanto una determinada concepción del tiempo, como de la relación con el propio cuerpo y la naturaleza. Frente a tal encrucijada, el objetivo de la ecología política consiste en "aumentar espacios para una socialización alternativa que permita la reapropiación tanto individual como colectiva del tiempo"65.

Ahora bien, como señala el economista francés Christophe Fourel -estudioso y actual promotor de la obra de Gorz- sobre el final de su vida Gorz se mostró escéptico sobre la posibilidad de que tal renta pueda introducirse gradual y pacíficamen-

63. GORZ, A., 2004, 95.

64. GORZ, A, 2005, 74.

65. FOUREL, 2010, 37. te a través de una reforma desde arriba. Por otra parte, el principal defensor de la renta básica en la actualidad, el filósofo y economista belga Philippe van Parijs, Ilama a tener cuidado con la propia idea de "autonomía", dado que "nada impide que las actividades autónomas sean contaminantes o reproduzcan la dominación"66.

\section{Conclusión}

En 2005, a los 80 años, Gorz publicó "Somos menos viejos que hace veinte años". Lo que nos envejece es ingresar en los dispositivos sociales que nos hacen que sea cada vez más difícil recomenzar. Su idea de "juventud" está asociada a no tener nada que perder al abandonar prácticas que, en definitiva, cercenan nuestra autonomía y restringen nuestra imaginación: "Conscientemente o no, hemos roto con nuestro pasado; somos menos viejos que hace cuarenta o veinte años, y muchos más jóvenes por nuestra convicción de que Otro mundo es posible"67.

Este trabajo ha pretendido señalar caminos, tensiones y puntos de inflexión por los que se concretan y se desvían las posibilidades de un mundo diferente en los cinco niveles señalados al comienzo. La conciencia sobre los límites biofísicos resulta necesaria, pero insuficiente para enfrentar las potencias de la globalización. Lo mismo sucede con los esfuerzos por poner límites políticos, incluso en los países con democracias afianzadas.

Más allá de las restricciones exteriores y del modo de superarlas, he buscado avanzar sobre las tensiones a nivel humano y sociocultural, donde son nuestros

66. VAN PARIJS, 2010, 52.

67. GORZ, A. 2010, 138. 
propios deseos de emulación -y una determinada concepción de la riqueza- los que llevan a que nuestras necesidades se vuelvan infinitas. En este caso, formamos parte del problema al generar la demanda del mundo en el que no queremos vivir. Aquí el combate es contra nuestra propia condición alienada, por lo que se vuelve relevante el contenido ético de nuestra conciencia individual.

He buscado reforzar el argumento y sentido del artículo de Jairo M. Pérez de la mano de dos de las figuras principales de los orígenes del movimiento decrecentista y en dos puntos específicos. Por un lado, al señalar que la idea de "convivencialidad" más que un concepto blando- puede colocarse como objetivo imprescindible de toda política del posdesarrollo. Las indicaciones dadas por Illich sobre cómo determinar -a través de una investigación radical- los umbrales de convivencialidad conducen a una reflexión consolidada y precisa sobre la relación entre consumo energético creciente y equidad decreciente.

Por otra parte, la idea de "convivencialidad" bajo el modelo de una sociedad dualista, permite visibilizar una retirada ordenada como un objetivo más realista para el movimiento decrecentista que la ruptura completa con la producción de mercancías y el dinero. En definitiva, lo fundamental consiste en emprender un viraje estratégico, un cambio de prioridades, actitudes y prácticas, una retirada ordenada que podemos comenzar o continuar... en cualquier momento.

\section{Bibliografía}

D’Alisa, G., Demaria, F., Kallis, G. (2015), Decrecimiento Un Vocabulario Para Una Nueva Era, Barcelona, Icaria.
Arendt, H. (2016), La condición humana, Buenos Aires, Paidós.

Bauman, Z., Lyon, D. (2013), Vigilancia Líquida, Buenos Aires, Paidós.

Bayón, D., Filpo, F., Schneider, F. (2012), Decrecimiento: 10 preguntas para entenderlo y debatirlo, Barcelona, El Viejo Topo.

Comins Mingol, I. (2009), Filosofía del Cuidar, una propuesta coeducativa para la paz, Barcelona, Icaria.

Deleuze, G., Guattari, F. (2002), Mil Mesetas: capitalismo y esquizofrenia, Valencia, Pretextos.

Fourel, C. (2010), "Itinerario de un pensador", en: A. Gorz, Escritos Inéditos, op. cit.

Georgescu Roegen, N. (1975), "Energy and Economic Myths", The Southern Economic Journal, 41. (2008), O Decrecimento: entropía, ecología, economía, Lisboa, Sang de la Terre.

Gorz, A. (1968), Estratégia Operaria e Neocapitalismo, Rio de Janeiro, Zahar. (2001), Adiós al Proletariado (más allá del socialismo), Barcelona, El Viejo Topo.

(2004), Miserias do Presente, Riqueza do posible, San Pablo, Annablume.

(2005), Lo Inmaterial: conocimiento, valor y capital, San Pablo, Annablume.

Barcelona, Paidós.

(2010), Escritos Inéditos, (2011), Ecológica, Buenos Aires, Capital Intelectual.

Holloway, J. (2011), Agrietar el Capitalismo: el hacer contra el trabajo, Buenos Aires, Herramienta.

Hopkins, R. (2008), The Transition Handbook. From oil dependency to local resilience, Totness, Green Books. 
Illich, I., (1975), Energía y Equidad, en: Obras Reunidas, vol. I, México: FCE, 2011.

(1978), La convivencialidad, en: Obras Reunidas, op. cit., pp. 370-530.

Jackson, T. (2011), Prosperidad sin crecimiento. Barcelona, Icaria.

Jonas, H. (2011), O Princípio Responsabilidade: ensaio de uma ética para a civilizaçao tecnologica, Rio de Janeiro, Contrapunto.

Kempf, H. (2011), Cómo los ricos destruyen el planeta, versión española J. Bucchi, Buenos Aires, Capital Intelectual

Latouche, S. (2009), Farewell to Growth, Cambridge: Polity Press.

(2014), Límite, Bue-

nos Aires: Adriana Hidalgo.

Layard, R. (2008), Felicidade: Liçoes de uma nova ciência, Rio de Janeiro, Best Seller: 2008.

Meadows, D., Meadows, D., Randers, J., Behrens III, W. (1972), The Limits of Growth, Nueva York, Universe Books.

Pérez, J.M. (2017), "Más allá del desarroIlo: decrecimiento", Revista Internacional de Pensamiento Político, vol. 12, pp. 467482.

Smart, A. (2014), El arte y la ciencia de no hacer nada, Buenos Aires, Capital Intelectual.

van Parijs, P. (2010), "De la esfera autónoma a la renta básica", en: A. Gorz, Escritos Inéditos, op. cit. 